\title{
BIRC5 is a novel target of peroxisome proliferator-activated receptor $\gamma$ in brain microvascular endothelium cells during cerebral ischemia
}

\author{
MINGJING XU ${ }^{1,2}$, XIANLI YANG ${ }^{3}$, QING ZENG ${ }^{1}, \mathrm{HE} \mathrm{HE}^{1}$, PENGCHENG LU $^{1}$ and GUOZHI HUANG ${ }^{1}$ \\ ${ }^{1}$ Department of Rehabilitation Medicine, Zhujiang Hospital, Southern Medical University, \\ Guangzhou, Guangdong 510282; Departments of ${ }^{2}$ Rehabilitation Medicine and ${ }^{3}$ Medical Quality Management, \\ Guizhou Provincial People's Hospital, Guiyang, Guizhou 550002, P.R. China
}

Received February 20, 2017; Accepted August 16, 2017

DOI: $10.3892 / \mathrm{mmr} .2017 .7750$

\begin{abstract}
Cerebral ischemia is a leading cause of ischemic stroke, which may lead to severe disability and mortality worldwide. There are some key factors concerned in cardioprotection, such as peroxisome proliferator-activated receptor $\gamma$ (PPAR $\gamma$ ), a ligand binding transcription factor involved in various biological functions including atherosclerosis, vascular dysfunction and hypertension, and baculoviral IAP repeat-containing 5 (BIRC5), which may protect human brain endothelial cells from ischemia-induced apoptosis To determine the potential roles of PPAR $\gamma$ in brain micro vascular endothelial (bEnd.3) cells during cerebral ischemia and the relationship between PPAR $\gamma$ and BLRC5, a cerebral ischemia model was established with bEnd.3 cells cells by oxygen-glucose deprivation (OGD) treatment. OGD treatment reduced proliferation and enhanced apoptosis of bEn 4.3 cells in a time-dependent manner. PPAR $\gamma$ expression levels were decreased in bEnd.3 cells following OGD treatment. Upregulation of PPAR $\gamma$ expression protected bEnd. 3 cells from ischemia injury and also upregulated BIRC5 expression. PPAR $\gamma$-specific binding sites in the BIRC5 promoter were predicted bioinformatically and yerified by luciferase reporter experiments. Results from electrophoretic mobility shift/supershift and chromatin immunoprecipitation assays suggested that BIRC5 may be a novel target of PPAR $\gamma$ transcriptional regulation during ischemic injury. The present results indicated that PPAR $\gamma$ may serve a protective role on
\end{abstract}

Correspondence to: Dr Guozhi Huang, Department of Rehabilitation Medicine, Zhujiang Hospital, Southern Medical University, 253 Gongye Road, Guangzhou, Guangdong 510282, P.R. China

E-mail: drhuang66@163.com

Key words: cerebral ischemia, cerebral microvascular endothelial cell, proliferator-activated receptor $\gamma$, baculoviral IAP repeat-containing 5
bEnd. 3 cells and that BIRC5 may be a downstream target of PPAR $\gamma$ regulation during cerebral ischemia.

Introduction

ebral ischemia leads to insufficient oxygen supply and ischemic stroke $(1,2)$, and is associated with a number of diseases or disorders (3). Microvascular endothelial cells can be activated during the hypoxia or ischemia, and by upregulating the expression levels of various agents, including proinflammatory mediators and adhesion molecules (4). Currently, there is no effective treatment or prevention available for the management of cerebral ischemia, and our knowledge is limited pertaining obrain microvascular endothelial (bEnd.3) cells during cerebral ischemia.

Peroxisome proliferator-activated receptors (PPARs) are ligand-activated transcription factors with three distinct isoforms (PPAR $\alpha$, PPAR $\gamma$ and PPAR $)(5,6)$. PPAR activation serves a role in anti-inflammatory effects in the brain and may serve as a novel pharmacological target for the management of neurological diseases $(7,8)$. Previous studies have revealed that brain ischemic injury enhanced the expression and activity of PPAR $\gamma$, and PPAR $\gamma$ agonists may protect neuron cells against brain ischemic injury $(9,10)$. However, the function of PPARs in bEnd.3 cells during cerebral ischemia remains unknown. Baculoviral IAP repeat-containing 5 (BIRC5; also known as survivin) belongs to the inhibitor of apoptosis (IAP) gene family that is widely expressed in cancer cells (11). Hypoxic preconditioning may protect brain endothelium from ischemia-induced apoptosis by Akt-dependent BIRC5 activation (12), which implied a potential connection between BIRC5 expression and human brain endothelium injury. BIRC5 was also reported to cooperate with PARP proteins in studies on cell cycle (13) or on cell proliferation in bladder cancer cells (14). In short, the potential role of BIRC5 in cerebral ischemia and its interaction with PPAR $\gamma$ need to be elucidated (15).

The present study demonstrated that PPAR $\gamma$ may protect cerebral microvascular endothelium against ischemia-reperfusion injury, and that BIRC5 may be a novel target of PPAR $\gamma$. These results may provide insights for future investigations 
considering the crucial role of PPAR regulators and targets in the pathogenesis of stroke.

\section{Materials and methods}

Cell culture. Mouse bEnd.3 cells were obtained from the American Type Culture Collection (ATCC; Manassas, VA, USA). All cells were maintained as previously described (16). Briefly, Cells were cultured in RPMI-1640 (Invitrogen; Thermo Fisher Scientific, Inc., Waltham, MA, USA) and supplemented with $15 \%$ fetal bovine serum (Sigma-Aldrich; Merck KGaA, Darmstadt, Germany), $100 \mathrm{U} / \mathrm{ml}$ penicillin and $100 \mathrm{U} / \mathrm{ml}$ streptomycin (Ameresco, Inc., Framingham, MA, USA). Cells were grown in a humidified atmosphere of 5\% $\mathrm{CO}_{2} / 95 \%$ air at $37^{\circ} \mathrm{C}$. The growth medium was replaced each day; cells were plated onto 96 -well plates or Petri dishes for further analysis.

Plasmid construction and transfection. The complete coding sequence of PPAR $\gamma$ (https://www.ncbi.nlm.nih.gov/gene/5468) was amplified and cloned into pcDNA4.1 vector (Invitrogen; Thermo Fisher Scientific, Inc.). The bEnd.3 cells $\left(2 \times 10^{5}\right.$ cells/well) were seeded into 24 -well plates and then pcDNA4.1-PPAR $\gamma$ overexpression plasmid (7 $\mu \mathrm{g} / \mathrm{ml}$, experimentalgroup) orempty pcDNA4.1 vector $(7 \mu \mathrm{g} / \mathrm{ml}$,control group) was transfected into bEnd. 3 cells using Lipofectamine 2000 (Invitrogen; Thermo Fisher Scientific, Inc.), following the manufacturer's instructions. The working concentration of plasmid was determined by previously study (17). After incubated at $37^{\circ} \mathrm{C}$ for $24 \mathrm{~h}$, cells that stably overexpressed PPAR $\gamma$ were selected and moved to new 24-well plates at a concentration of $2 \times 10^{5}$ cells/well, after incubated overnight at $37^{\circ} \mathrm{C}$, cells were treated with oxygen-glucose deprivation (OGD) for $12 \mathrm{~h}$ to establish an ischemic cell model, then western blot analy and immunofluorescence assay were used to measure the expression of PPAR $\gamma$ in these ceis

Preparation of OGD model. To mimic ischemic conditions in vitro, bEnd. 3 cells $\left(2 \times 10^{5} \mathrm{cell} / \mathrm{ml}\right)$ were exposed to OGD. Cell cultures were subjected to ischemia-like injury through OGD for 3, 6 and $12 \mathrm{~h}$ by placing cultures in a Forma Anaerobic Chamber (Thermo Fisher Scientific, Inc.) with an atmosphere of $\mathrm{O}_{2}$ tension $<0.2 \%\left(5 \% \mathrm{CO}_{2}, 5 \% \mathrm{H}_{2}\right.$ and $\left.90 \% \mathrm{~N}_{2}\right)$ in a deoxygenated glucose-free balanced salt solution. Cultures were placed in a humidified incubator at $37^{\circ} \mathrm{C}$. Cultured cells and media were harvested by trypsinization and re-suspended in PBS, and then centrifugation at $16,000 \mathrm{xg}$ for $10 \mathrm{~min}$ at $4^{\circ} \mathrm{C}$ as previously described $(18,19)$ at different time points for further experiments.

Proliferation assays. The proliferative ability of bEnd. 3 cells was measured using the Cell Counting Kit-8 (CCK-8), according to the manufacturer's instructions. The bEnd. 3 cells were seeded into 24 -well plates at a concentration of $2 \times 10^{5}$ cells/well, and incubated overnight at $37^{\circ} \mathrm{C}$. After treated with OGD for 0 , 3,6 or $12 \mathrm{~h}, \mathrm{CCK}-8$ solution $(10 \mu \mathrm{l})$ was added to 96 -well plates incubated at $37^{\circ} \mathrm{C}$ for $4 \mathrm{~h}$ in $5 \% \mathrm{CO}_{2}$, and the absorbance of each well was detected using a microplate reader (Multiskan Spectrum; Thermo Fisher Scientific, Inc., Waltham, MA, USA) at a wavelength of $450 \mathrm{~nm}$.
The 5-ethynyl-29-deoxyuridine (EdU) Cell-Light Apollo DNA in vitro Imaging kit (Guangzhou RiboBio Co., Ltd., Guangzhou, China) was also used to examine proliferative ability. Cells ( $1 \times 10^{5}$ cells/dish) were cultured in Petri dishes for $24 \mathrm{~h}$ at $37^{\circ} \mathrm{C}$. Following OGD treatment, $50 \mu \mathrm{M}$ of EdU was added to each dish and cells were cultured for an additional $2 \mathrm{~h}$ at $37^{\circ} \mathrm{C}$, and then cells stained with EdU were analyzed using the CellQuest Flow Cytometry System version 5.1 (BD Biosciences, Franklin Lakes, NJ, USA).

RNA extraction and reverse transcription-quantitative polymerase chain reaction $(R T-q P C R)$. The assay of qRT-PCR was performed as previously described (20). Briefly, total RNA was extracted from the cultured bEnd 3 cells $\left(2 \times 10^{5}\right.$ cells $\left./ \mathrm{ml}\right)$ using TRIzol reagent (Invitrogen; Thermo Fisher Scientific, Inc.), according to the manufacturer's instructions. RNA was reverse transcribed using, and qRCR was performed with an ABI 9700 PCR Thermal Cycler and an SYBR-Green kit (Bio-Rad Laboratories, Inc., Hercules, CA, USA) according to the manufacturer's instructions. Briefly, qRT-PCR was performed using $10 \mu \mathrm{P} 2$ X SYBR-Green PCR Master Mix (Toyobo Life Science, Osaka, Japan), with $5 \mu \mathrm{l}$ of cDNA, $0.5 \mu 1$ of primers and $4 \mu \mathrm{N}$ of RNase-free $\mathrm{ddH}_{2} \mathrm{O}$ contained in $20 \mu \mathrm{l}$ of reaction mixture. The reaction was performed with one cycle of $95^{\circ} \mathrm{C}$ for $5 \mathrm{~min}$ and 40 cycles of $95^{\circ} \mathrm{C}$ for $15 \mathrm{sec}, 65^{\circ} \mathrm{C}$ for $15 \mathrm{sec}$ and $72^{\circ} \mathrm{C}$ for $35 \mathrm{sec}$ in ABI 7300 real-time PCR instrument (Applied Biosystems; Thermo Fisher Scientific, Inc.). When the reaction proceeded. $\mathrm{Ct}$ value was obtained, and results were analyzed using $2^{-\Delta \Delta C q}$ calculation (20). $\beta$-actin was used to normalize the data. The primer sequences were: $\beta$-actin forward, 5'-CATTGCTGACAGGATGCAGA-3' and reverse, 5'-CTGCTGGAAGGTGGACAGTGA-3'; PPAR $\gamma$ forward, 5'-GGAAGACCACTCGCATTCCTT-3' and reverse, 5'-GTAATCAGCAACCATTGGGTCA-3'; BIRC5 forward, 5'-GAGGCTGGCTTCATCCACTG-3' and reverse, 5'-ATGC TCCTCTATCGGGTTGTC-3'. $\beta$-actin was used as an internal control.

Apoptosis assay. Apoptotic rates were examined by flow cytometric analysis using Annexin V staining kit (BD Pharmingen; BD Biosciences). The transfected bEnd.3 cells $\left(1 \times 10^{6}\right.$ cells $\left./ \mathrm{ml}\right)$ or untransfected bEnd 3 cells $\left(1 \times 10^{6}\right.$ cells $\left./ \mathrm{ml}\right)$ were collected by trypsinization and the suspensions centrifuged at $16,000 \mathrm{x} \mathrm{g}$ for $10 \mathrm{~min}$ at $4^{\circ} \mathrm{C}$. Cells $\left(1 \times 10^{6} \mathrm{cells} / \mathrm{ml}\right)$ were resuspended in $1 \mathrm{X}$ binding buffer (BD Biosciences). Subsequently, $100 \mu \mathrm{l}$ of this solution $\left(\sim 1 \times 10^{5}\right.$ cells $)$ was transferred to a 5-ml culture tube. Annexin V (5 $\mu \mathrm{l})$ and propidium iodide (5 $\mu \mathrm{l}$; BD Biosciences), used for apoptosis signal detection, were added to the samples, and then incubated for $15 \mathrm{~min}$ at room temperature in the dark. A total of $400 \mathrm{ml} \mathrm{1X}$ binding buffer was added to each tube and the samples were immediately analyzed by BD FACSCanto II flow cytometry (BD Biosciences). The data were analyzed by FlowJo software version 8.8.6 (FlowJo LLC, Ashland, OR, USA). For the Hoechst staining, treated or control cells were seeded in 24-well plates at a concentration of $1 \times 10^{6}$ cells/well and incubated overnight at $37^{\circ} \mathrm{C}$, and the DNA content of cells in each well were stained with $100 \mu \mathrm{l}$ of Hoechst 33342 for $30 \mathrm{~min}$ followed by DAPI staining for $10 \mathrm{~min}$ at room temperature and visualized under a fluorescence microscope 
(Olympus, Tokyo, Japan). Experiments were performed in triplicate.

Western blotting. Cell samples $\left(2 \times 10^{6}\right.$ cells $\left./ \mathrm{ml}\right)$ were lysed in $4^{\circ} \mathrm{C}$ for at least $30 \mathrm{~min}$ by radioimmunoprecipitation assay buffer (Beyotime Institute of Biotechnology, Haimen, China) to obtain total cell lysates. Protein concentrations were determined using the Bicinchoninic Acid Protein assay kit (Thermo Fisher Scientific, Inc.). Similar amounts of protein ( $40 \mu \mathrm{g})$ from each sample were separated by $10 \%$ SDS-PAGE and transferred to polyvinylidene fluoride membranes (Merck KGaA, Darmstadt, Germany). Membranes were incubated with primary rabbit polyclonal antibodies against PPAR $\gamma$ (ab59256, 1:1,000) and BIRC5 (ab469, 1:1500) (both from Abcam, Cambridge, MA, USA) overnight at $4{ }^{\circ} \mathrm{C}$, followed by incubation with horseradish peroxidase-conjugated monoclonal goat anti-rabbit immunoglobulin (Ig)G (BA1054, 1:2,000; Boster Biological Technology, Pleasanton, CA, USA) at room temperature for $2 \mathrm{~h}$. Membranes were stripped and reprobed with a primary monoclonal mouse anti-rabbit antibody against GAPDH (KF703, 1:1,000; Nanjing Jiancheng Bioengineering Institute, Nanjing, China, ). Protein bands were quantified by densitometry using the gel analysis software ImageJ (National Institutes of Health, Bethesda, MD, USA).

Dual-luciferase reporter assay. The BIRC5 promoter binding site sequence (gene ID, 11799) for PPAR $\gamma$ was predicted using Ensembl(http://www.ensembl.org/Multi/Tools/Blast?db=core) and NCBI (https://blast.ncbi.nlm.nih.gov/Blast cgi?PROGRAM=blastn\&PAGE_TYPE=BlastSeareh\&LINK LOC=blasthome). Wild-type (WT) BIRC5 promoter and mutated (MUT) promoter sequence containing the predicted target sites were synthesized and cloned into the $\mathrm{XbaI}$ and Fse restriction sites of a pGL3 control vector (Promega, Madison, WI, USA); the constructs were termed pGL3-promoter-WT and pGL3-promoter-MUT. In the reporter assay experiment, bEnd. 3 cells $\left(1 \times 10^{3}\right.$ cells/well) were seeded onto 24 -well plates and transfected with either pGL3-promoter-WT or pGL3-promoter-MUT, and co-transfected with the pcDNA4.1-PPAR $y$ or pcDNA4.1 controlvectors using Lipofectamine 2000 (Invitrogen; Thermo Fisher Scientific, Inc.), following the manufacturer's instructions at $4^{\circ} \mathrm{C}$ for $2 \mathrm{~h}$. A Renilla luciferase vector, pRL-SV50 (Promega), was also co-transfected into the cells and used to normalize the differences in firefly luciferase activities. Following $48 \mathrm{~h}$ transfection, cells were harvested and luciferase activities were measured with the Dual-Luciferase Reporter Assay System (Promega), according to the manufacturer's instructions. Transfections were repeated in triplicate in three independent experiments.

Immunofluorescence assay. PPAR $\gamma$ protein expression levels were also evaluated by immunofluorescence. Treated bEnd. 3 cells $\left(1 \times 10^{5}\right.$ cells $\left./ \mathrm{ml}\right)$ were seeded into 6 -well plates overnight at $37^{\circ} \mathrm{C}$. Then, the cells were fixed by $4 \%$ paraformaldehyde for $24 \mathrm{~h}$, and blocked with $1 \%$ bovine serum albumin for $2 \mathrm{~h}$ at room temperature and incubated with anti-PPAR $\gamma$ antibody (cat. no. ab209350, 1:200; Abcam, Cambridge, UK) overnight at $4^{\circ} \mathrm{C}$ and then incubated with $1 \mu \mathrm{g} / \mathrm{ml}$ DAPI dihydrochloride; D9542; Sigma-Aldrich; Merck $\mathrm{KGaA}$ ) at room temperature for $10 \mathrm{~min}$. Fluorescence images of six random fields were captured on a Nikon Eclipse Ti-U fluorescence microscope (Nikon, Tokyo, Japan) equipped with a SPOT-RTTM digital camera (Diagnostic Instruments, Inc., Sterling Heights, MI, USA). The fluorescent images were visualized with a Leica fluorescence microscope (Leica Microsystems GmbH, Wetzlar, Germany). Each experimental was replicated three times.

Electrophoretic mobility shift assay (EMSA) and supershift assay. Nuclear proteins from bEnd.3 cells $\left(1 \times 10^{6}\right.$ cells $\left./ \mathrm{ml}\right)$ were extracted using the NE-PER ${ }^{\circledR}$ Nuclear Extraction Reagent (Thermo Fisher Scientific, Inc.) according to a previously described protocol (21). The treated cells were washed for three times with cold phosphate-buffered saline (PBS; pH 7.4), the cells were then scraped and centrifuged at 15,000 $\mathrm{x} g$ for $5 \mathrm{~min}$, to collect the pellets. Biotin-labeled PPAR $\gamma$ specific oligonucleotides (Invitrogen; Thermo Fisher Scientific, Inc.), with the following sequence, 5'-AAAGGAGGTTAGAGG GGAAGGGGCGTAG-'3, were prepared as labeled probes, according to the manufacturer's instructions (Promega). Double-stranded oligonucleotides forPPAR $\gamma$ were end-labeled with adenosine-5'-triphosphate (ATP) $-\gamma-{ }^{32} \mathrm{P}$ using the T4 polynucleotide kinase (Promega), according to the manufacturer's instructions. Biotin end-labeled double-stranded DNA and the nuclear extracts were incubated at room temperature for $20 \mathrm{~min}$, and then $10 \mu \mathrm{l}$ protein-DNA complex was subjected to $6.5 \%$ PAGE at $100 \mathrm{~V}$ for $1 \mathrm{~h}$ at $4^{\circ} \mathrm{C}$ and transferred onto a nylon membrane. The radiolabeled probes were purified by spin columns (Roche Applied Science, Penzberg, Germany). Nuclear protein extracts $(5 \mu \mathrm{g})$ from bEnd.3 cells were incubated with $100,000 \mathrm{cpm}{ }^{32} \mathrm{P}$-labeled oligonucleotide probe in $25 \mathrm{mM}$ HEPES (pH 7.4), $50 \mathrm{mM} \mathrm{KCl,} 10 \%$ glycerol (v/v), $5 \mathrm{mM}$ dithiothreitol and $1 \mu \mathrm{g}$ of poly (deoxyinosinic-deoxycytidylic) acid (GE Healthcare Life Sciences, Shanghai, China) for $30 \mathrm{~min}$ at room temperature in a final volume of $20 \mu \mathrm{l}$. Following binding, protein-DNA complexes were separated on a $6 \%$ non-denaturing polyacrylamide gel at $120 \mathrm{~V}$ in $0.5 \mathrm{X}$ Tris/borate/EDTA buffer. Gels were analyzed with a PhosphorImager Gel Imaging System (Bio-Rad Laboratories, Inc.). For the antibody supershift analysis, $1 \mu \mathrm{g}$ of antibody against PPAR $\gamma$ (ab59256; Abcam) was added to the nuclear extracts at a dilution of 1:1,000 for $16 \mathrm{~h}$ prior to addition of the radiolabeled oligonucleotides.

Chromatin immunoprecipitation (ChIP) assay. Cells $\left(5 \times 10^{7}\right)$ were fixed with $4 \%$ paraformaldehyde for $10 \mathrm{~min}$ at $37^{\circ} \mathrm{C}$ and a ChIP assay was performed with the EZ-ChIP assay kit (Sigma-Aldrich; Merck KGaA), as previously described (22). Briefly, Pellet cells were resuspended by SDS lysis buffer with $1 \%$ protease inhibitor cocktail set III EDTA-free (Calbiochem; Merck KGaA) and incubated for $10 \mathrm{~min}$ on ice. Sonicate lysate to shear DNA to lengths between 500-1,000 bp which were detected by $1 \%$ ethidium bromide gel electrophoresis. The conditions have been optimized following steps number of bursts: 8 , length of bursts: $10 \mathrm{sec}$, interval time: $10 \mathrm{sec}$, output control setting: $30 \%$, duty cycle: constant. The lysates were incubated with anti-PPAR $\gamma$ antibody (ab59256, 1:10; Abcam) or a rabbit control IgG (ab6789, 1:500; Abcam) for $24 \mathrm{~h}$ at $4^{\circ} \mathrm{C}$, and the complexes were isolated using protein A-agarose/salmon sperm DNA (EMD Millipore, Billerica, 
MA, USA). Immunoprecipitates were added in $1 \mathrm{ml}$ of high-salt wash buffer for ChIP to all samples and rotated for $10 \mathrm{~min}$ at room temperature; the samples were centrifuged at $4500 \mathrm{x} \mathrm{g}$ for $2 \mathrm{~min}$ at room temperature; the supernatants were carefully aspirated and added $1 \mathrm{ml}$ of high-salt wash buffer for ChIP; the samples were rotated for $10 \mathrm{~min}$ at room temperature; the above two steps were repeated twice in a total of four high-salt washes; the supernatants were aspirated and washed twice with TE as above. Immunoprecipitates were subsequently eluted with freshly prepared $1 \% \mathrm{SDS}+0.1 \mathrm{M}$ $\mathrm{NaHCO}_{3}$ buffer. To the immune complexes were added $20 \mu \mathrm{l}$ $5 \mathrm{M} \mathrm{NaCl}$ and histone-DNA crosslinks reversed by heating at $65^{\circ} \mathrm{C}$ for $4 \mathrm{~h}$. Following the reversing of crosslinking, DNA was purified with the QIAquick PCR Purification kit (Qiagen $\mathrm{GmbH}$, Hilden, Germany) followed by PCR amplification. The amplification reactions were performed using Amplitaq DNA polymerase, GeneAmp dNTPs (deoxynucleoside triphosphates) with dUTP, and AmpErase UNG (all from PerkinElmer, Inc., Waltham, MA, USA). The thermocycling conditions were a thermal cycler preheated to $94^{\circ} \mathrm{C}$; and then $94^{\circ} \mathrm{C}$ for $1 \mathrm{~min}, 55^{\circ} \mathrm{C}$ for $1 \mathrm{~min}, 72^{\circ} \mathrm{C}$ for $2 \mathrm{~min}$ for 30 cycles and a final extension at $72^{\circ} \mathrm{C}$ for $7 \mathrm{~min}$. The PCR-amplified products were examined by electrophoresis in a $1.5 \%$ agarose gel, stained with a $1 \%$ solution of ethidium bromide, and examined under ultraviolet illumination. Primers used to amplify the PPAR $\gamma$ binding site area were: Forward, 5'-TCCCTTCCA ACCTCCCAAT-3' and reverse, 5'-AGCCCAGTATCCCAA ATCAAC-3', which resulted in a 98 bp fragment. PCR products were resolved by $2 \%$ agarose gel electrophoresis, visualized by ethidium bromide staining and analyzed by densitometry using ImageJ software version 1.37 (National Institutes of Health, Bethesda, MD, USA). To ensure the specificity of each assay, DNA binding in normal $\mathrm{IgG}$ immunoprecipitates was regarded as the background control.

Statistical analysis. All experiments were performed at least three times, and all samples were tested in triplicate. Experimental data are displayed as the mean \pm standard deviation. All analyses were performed using one-way analysis of variance or an unpaired Student's t-test performed on SPSS software, version 12.0 (SPSS, Inc., Chicago, IL, USA). P<0.05 was considered to indicate a statistically significant difference.

\section{Results}

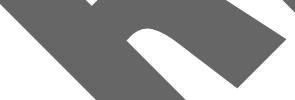

$O G D$ reduces proliferation and enhances apoptosis of bEnd.3 cells. To establish a cerebral microvascular endothelial cell injury model with cerebral ischemia, bEnd.3 cells were exposed to OGD conditions to mimic ischemia-like conditions in vitro. Following OGD treatment, bEnd.3 cells exhibited a significant decrease in proliferation capacity in a time-dependent manner (Fig. 1A), with the group treated for $12 \mathrm{~h}$ exhibiting $\sim 60 \%$ loss in cell viability compared with the control group (treated for $0 \mathrm{~h}$ ). To confirm cell viability, the proliferation capacity of bEnd. 3 cells post-treatment was examined by EdU incorporation and flow cytometry; the M2 phase rate was $11.9 \%$, much lower compared with the control group (36.7\%; Fig. 1B). The results demonstrated that viability in bEnd. 3 cells significantly decreased following OGD treatment in a time-dependent manner.

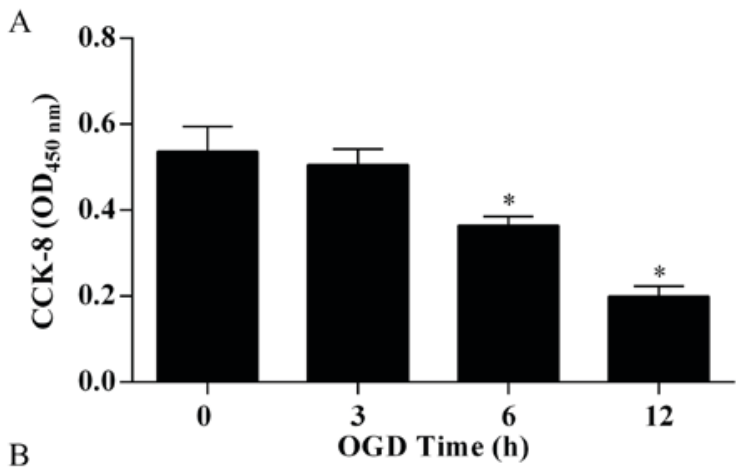

B

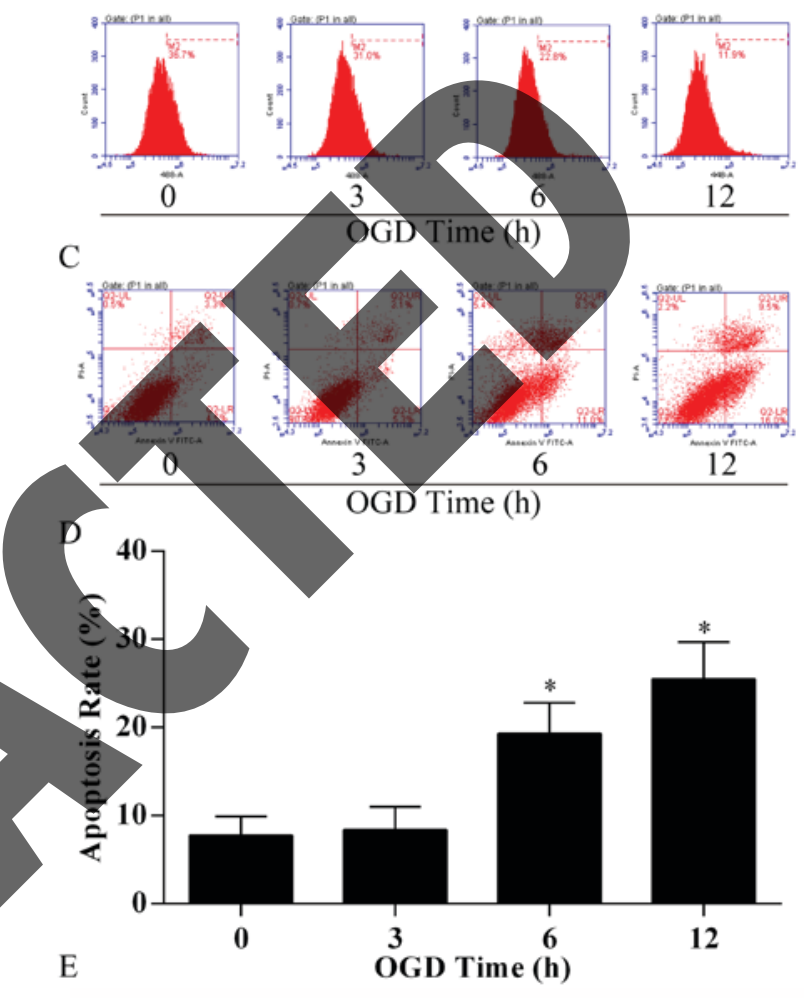

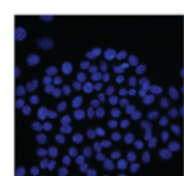

0

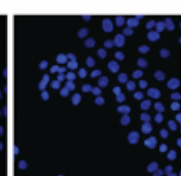

3

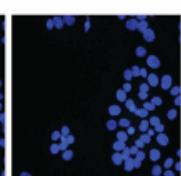

6

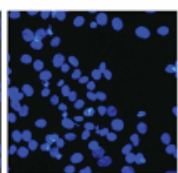

12
Figure 1. Effects of OGD treatment on bEnd. 3 cell proliferation and apoptosis at different treatment durations. (A and B) The effects of OGD treatment on the proliferation of bEnd.3 cells in vitro were detected by (A) CCK-8 assay and (B) EdU incorporation/flow cytometry assay. (C) Apoptotic cells were assessed by Annexin V/PI staining and flow cytometry assay. (D) Total percentage of apoptotic cells (from part C) in the 6 and 12 h OGD treatment groups were significantly higher compared with the $0 \mathrm{~h}$ control group. (E) Apoptosis was also observed by Hoechst staining (magnification, $\mathrm{x} 40$ ); the number of apoptotic cells notably increased in a treatment time-dependent manner. Data are presented as the mean \pm standard deviation of the mean; $\mathrm{n}=3$ independent experiments; ${ }^{*} \mathrm{P}<0.05$. CCK-8, Cell Counting Kit-8; FITC, fluorescein isothiocyanate; OGD, oxygen-glucose deprivation.

The effects of OGD treatment on apoptosis in bEnd.3 cells were examined using the apoptosis assay by flow cytometry analysis and Annexin V/PI staining. OGD-treated cells exhibited an increase in the proportion of early apoptotic cells $(5.3 \%$ in $3 \mathrm{~h}$ treatment group, $11.0 \%$ in $6 \mathrm{~h}$ treatment group and $16.0 \%$ in $12 \mathrm{~h}$ treatment group) and late apoptotic cells (3.1\% in $3 \mathrm{~h}$ 


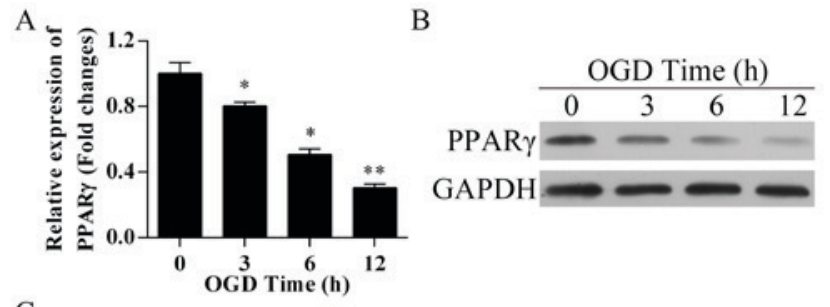

$\mathrm{C}$

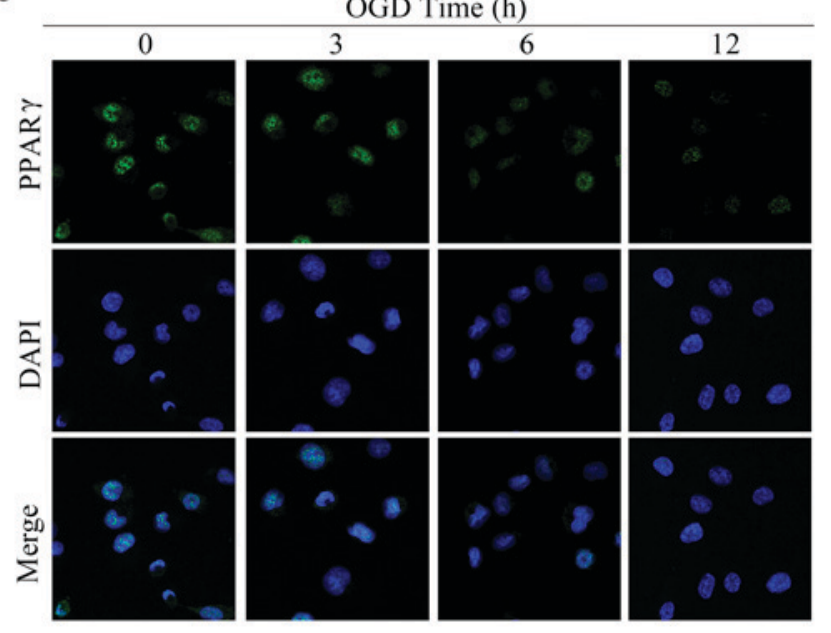

Figure 2. PPAR $\gamma$ expression levels in bEnd. 3 cells following different OGD treatment durations. (A) PPAR $\gamma$ mRNA expression was analyzed by reverse transcription-quantitative polymerase chain reaction. (B) PPAR $\gamma$ protein expression was analyzed by western blotting. (C) Immunofluorescence staining of PPAR $\gamma$ protein in bEnd. 3 cells following different OGD treatments (magnification, $\mathrm{x} 40$ ). Data are presented as the mean \pm standard deviation of the mean; $\mathrm{n}=3$ independent experiments; ${ }^{*} \mathrm{P}<0.05$ and ${ }^{* *} \mathrm{P}<0.01$ vs. $0 \mathrm{~h}$ control OGD, oxygen-glucose deprivation; PPAR $\gamma$, proliferator-activated receptor $\%$

treatment group, $8.3 \%$ in $6 \mathrm{~h}$ treatment group, $9.5 \% \mathrm{in} 12 \mathrm{~h}$ treatment group), compared with $4.5 \%$ (early) and $3.3 \%$ (late) in the $0 \mathrm{~h}$ control group (Fig. 1C), which resulted in an overall threefold enhancement in total cell apoptosis in the $12 \mathrm{~h}$ treatment group compared with the control $(\mathrm{P}<0.05$, Fig. $\mathrm{DD})$. Following incubation and treatment, bEnd. 3 cell nuclei were stained with Hoechst, and notable changes in cell apoptosis were observed, as the Hoechst nuetear staining became increasingly bright with the longer durations of OGD treatment (Fig. 1E).

PPAR expression is inhibited by OGD treatment. To evaluate the status of PPAR $\gamma$ expression following OGD treatments of bEnd. 3 cells, PPAR $\gamma$ mRNA and protein expression levels were detected. RT-gPCR analysis and western blotting revealed that the OGD treatment led to reduction in PPAR $\gamma$ mRNA and protein expression levels (Fig. 2A and B, respectively), and this decrease occurred in a time-dependent manner. To examine the PPAR $\gamma$ protein expression status in situ, immunofluorescence staining was performed (Fig. 2C). Untreated bEnd.3 cells ( $0 \mathrm{~h}$ control) exhibited uniform distribution of PPAR $\gamma$ expression compared with OGD-treated cells, which obtained exhibited a faint staining pattern. These results confirmed that PPAR $\gamma$ expression was inhibited in bEnd. 3 cells treated with OGD.

PPAR $\gamma$ protects brain endothelium from ischemic apoptosis. A previous report suggested that PPAR $\gamma$ activation may protect neural cells following cerebral ischemia (23);
A

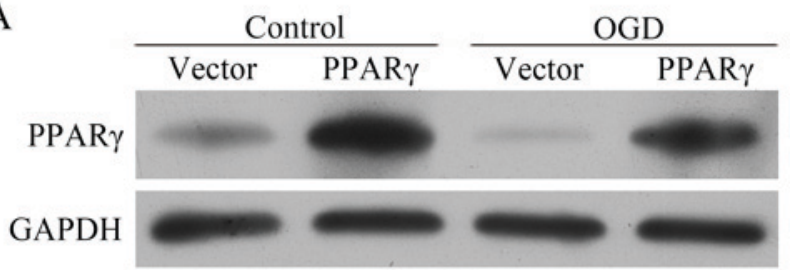

B

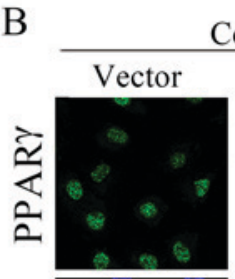

Control
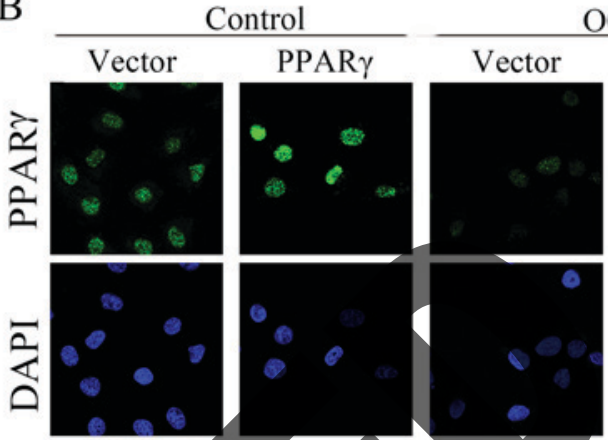

OGD
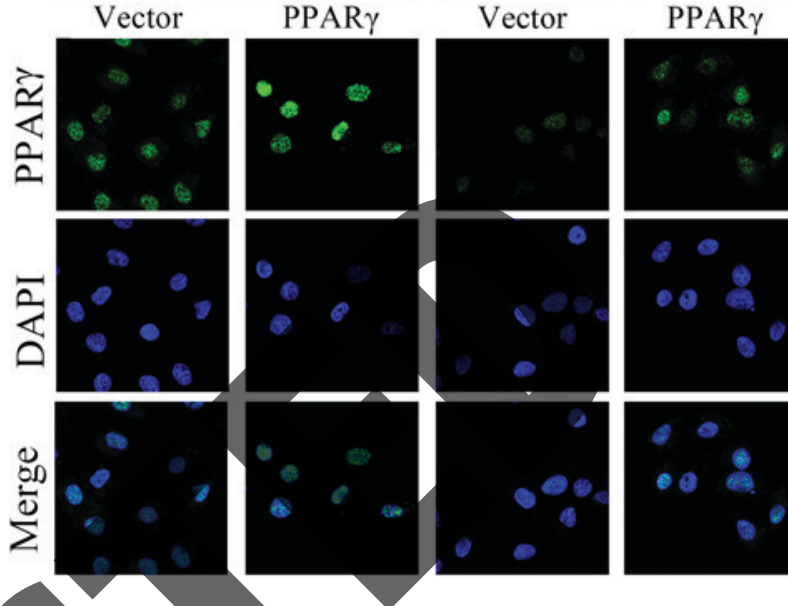

Figure

3. PPAR $\gamma$ expression levels in bEnd.3 cells transfected with PPAR $\gamma$
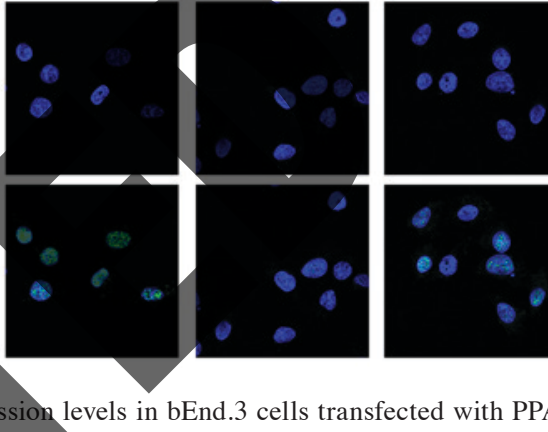

levels were analyzed by western blotting. (B) PPAR $\gamma$ immunofluorescence staining in bEnd. 3 cells following OGD treatment; nuclei are stained with DAPI (magnification, $\mathrm{x} 40$ ). OGD, oxygen-glucose deprivation; PPAR $\gamma$, proliferator-activated receptor $\gamma$.

therefore, the present study hypothesized that the upregulation of PPAR $\gamma$ gene expression may also relieve cerebral microvascular endothelial cells from cerebral ischemia injury. To examine this, bEnd.3 cells were transfected with pcDNA4.1-PPAR $\gamma$ overexpression plasmid, which exhibited a notable increase in PPAR $\gamma$ protein expression levels compared with cells transfected with the pcDNA4.1-empty vector control, in the presence or absence of OGD treatment (Fig. 3A). No significant difference was observed between bEnd.3 cells transfected with pcDNA4.1-PPAR $\gamma$ overexpression plasmid and pcDNA4.1-empty vector control without the treatment of OGD. However, in the presence of OGD treatment, the PPAR $\gamma$ expression was significantly higher in the PPAR $\gamma$ overexpressed bEnd. 3 cells compared with the vector group (Fig. 3B).

PPAR $\gamma$ overexpression alleviates bEnd.3 cell death caused by 12 h OGD exposure. Results from live cell counts demonstrated that the cell viability recovered more than $50 \%$ in the bEnd.3 cells transfected with pcDNA4.1-PPAR $\gamma$ overexpression plasmid compared with those cells transfected with the empty vector (Fig. 4A). Proliferation capacity of bEnd.3 cells was also analyzed by EdU incorporation assay (Fig. 4B); M2 phase rate was notably higher $(\sim 17 \%)$ in OGD-treated cells that were transfected with the PPAR $\gamma$ overexpression plasmid compared with OGD-treated cells transfected with the empty vector $(8.8 \%)$. No significant differences in viability were identified in bEnd.3 cells transfected with pcDNA4.1-PPAR $\gamma$ plasmid compared with the control groups (Fig. 4A and B). 


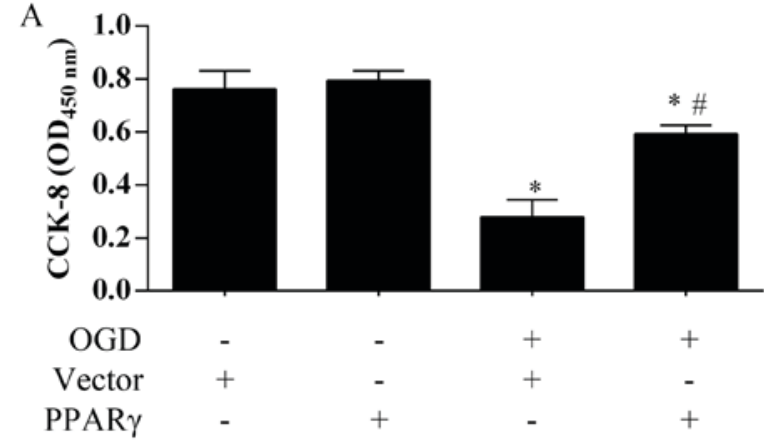

$\mathrm{B}$
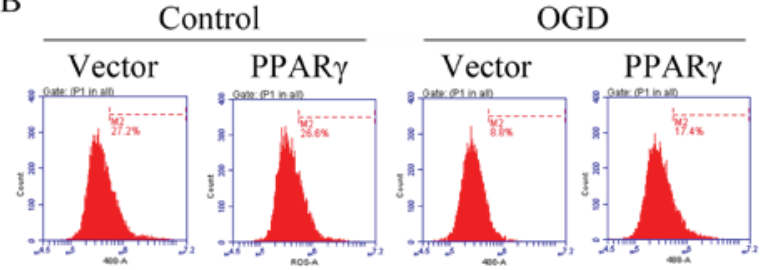

C

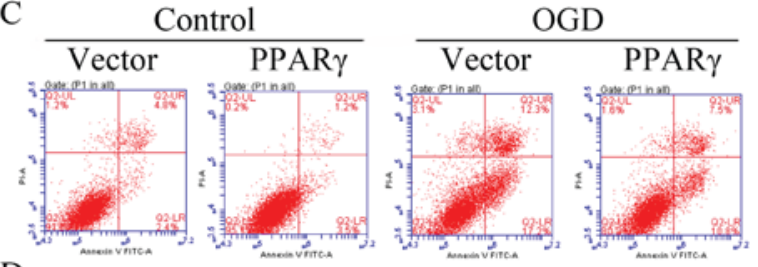

$\mathrm{D}$
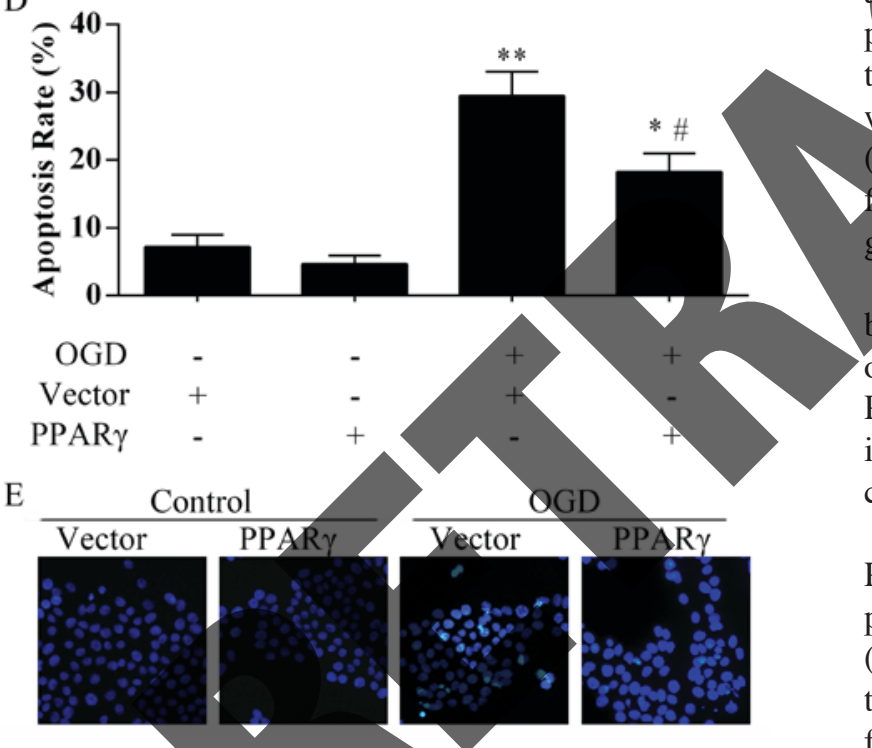

Figure 4. Effects of OGD treatment on bEnd. 3 cells with PPAR $\gamma$ overexpression. The effects of OGD treatment on in vitro bEnd. 3 cell proliferation were examined by (A) CCK-8 and (B) EdU incorporation assay in different treatment groups. (C) Apoptotic cells were assessed by Annexin V/PI staining and flow cytometry assay. (D) The percentage of apoptotic cells in the treatment groups were significantly higher compared with in the control group. (E) Apoptosis was also observed by Hoechst staining; the number of apoptotic cells increased in a treatment time-dependent manner. Data are presented as the mean \pm standard deviation of the mean; $n=3$ independent experiments; ${ }^{*} \mathrm{P}<0.05$ and ${ }^{* *} \mathrm{P}<0.01$ vs. vector-only; ${ }^{*} \mathrm{P}<0.05$ vs. OGD-treatment without PPAR $\gamma$. CCK-8, Cell Counting Kit-8; FITC, fluorescein isothiocyanate; OGD, oxygen-glucose deprivation; PPAR $\gamma$, proliferator-activated receptor $\gamma$.

In the Annexin V/PI apoptosis assay, the proportion of total apoptotic cells was observed to be $7.2 \%$ in the control group, $4.7 \%$ in the PPAR $\gamma$ overexpression group, $29.5 \%$ in the OGD treatment group and $18.3 \%$ in the OGD-treated cells that overexpressed PPAR $\gamma$ (Fig. 4C and D), which indicated that
PPAR $\gamma$ may significantly inhibit apoptosis under ischemia-like conditions. Hoechst nuclear staining also demonstrated that PPAR $\gamma$ overexpression may rescue bEnd .3 cell death following OGD treatment (Fig. 4E).

BIRC5 expression is regulated by PPAR $\gamma$ during ischemia. To further determine the molecular mechanisms responsible for PPAR $\gamma$-mediated protective roles in the OGD treatment process, the expression of another critical factor that also serves important roles in ischemic apoptosis, BIRC5, was examined. BIRC5 mRNA expression was significantly decreased in bEnd.3 cells following OGD treatment, compared with control cells (Fig. 5A); this reduced expression was recovered in OGD-treated cells that overexpressed PPAR $\gamma$. Similar results were obtained in western blot analyses of BIRC5 protein expression (Fig. 5B). These results indicated that BIRC5 expression may be regulated at both the mRNA and the protein level by PPAR $\gamma$ during ischemic conditions.

$B I R C 5$ is a target of $P P A R \gamma$ regulation. To elucidate the mechanisms of PPAR $\gamma$ regulation on BIRC5, a functional analysis was performed to verify the potential PPAR $\gamma$ binding sites in the BIRC5 promoter. The transcriptional responses of the BIRC5 pGL-płomoter-WT and pGL-promoter-MUT plasmids were analyzed using an in vitro luciferase transcriptional assay (2). pcDNA4.1-PPAR $\gamma$ overexpression significantly increased the transcriptional activity of the pGL-promoter-WT, compared with cells co-transfected with the empty pcDNA4.1 vector (Fig. 5C). Conversely, no significant differences were identified in the luciferase activities of the pGL-promoter-MUT group co-transfected with the PPAR $\gamma$ overexpression vector.

ChIP analysis was applied to verify the interaction between PPAR $\gamma$ and BIRC5 promoter. Consistent with previously reported transcriptional activity, a significant increase in PPAR $\gamma$ binding to the BIRC5 promoter site was detected, with isotypic $\operatorname{IgG}$ antibody used as a negative immunoprecipitation control $(\mathrm{P}<0.01$; Fig. 5D).

EMSA supershift assay was applied to determine whether PPAR $\gamma$ was able to bind to the BIRC5 promoter. The PPAR $\gamma$ protein formed a complex band (shift band) using probes (Fig. 5E). By contrast, the PPAR $\gamma$ protein competitor prevented the formation of the shift band, which indicated that it interfered DNA binding. Specificity of binding was examined with a mutated competitor, which failed to elicit competition, as demonstrated in the unaltered band formation. The specificity of the complex was reconfirmed using a PPAR $\gamma$ antibody that supershifted the PPAR $\gamma+$ BIRC5 band. These data suggested that BIRC5 may be a novel target of PPAR $\gamma$ transcriptional regulation.

\section{Discussion}

Cerebral microvascular endothelial cells serve a major role in ischemic insult of the brain, and regulate the trafficking of cells, substrates and other molecules across the blood-brain barrier, vasomotor reactivity and homeostasis at the interface of the blood/vascular wall. Neurovascular protection is considered as an effective part of stroke therapy $(6,24)$. Elucidation of the underlying mechanism of different regulators and bEnd.3 cells may provide new insights into the cerebral vasculature and 
A

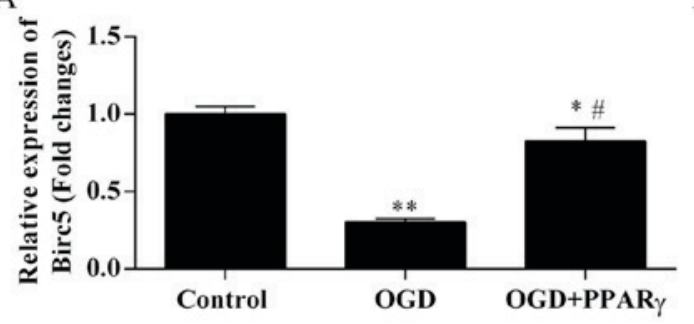

B

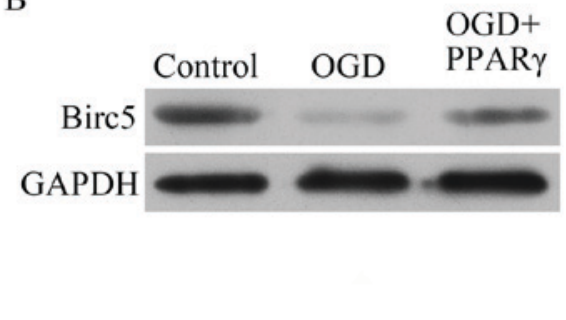

$\mathrm{C}$

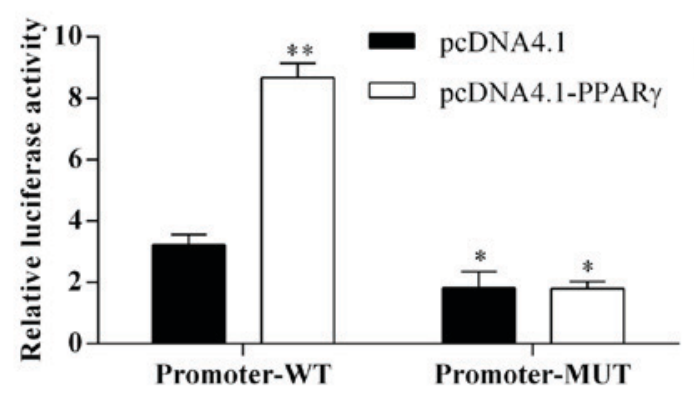

E

D

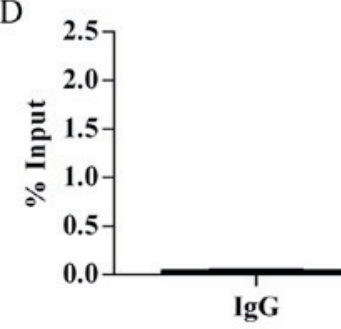

Promoter-MUT


Figure 5. Validation of BIRC5 as a target of PPAR $\gamma$. The expression levels of BIRC5 in bEnd.3 cells following OGD treatment with or without PPAR overexpression were analyzed by (A) reverse transcription-quantitative polymerase chain reaction and (B) western blot analysis. Data are presented as the mean \pm standard error of the mean; $n=3$ independent experiments; ${ }^{P}<0.05$ and ${ }^{*} \mathrm{P}<0.01$ vs. control; ${ }^{~} \mathrm{P}<0.05$ vs. OGD treatment. (C) The luciferase assay was used to test the targeting relationship between PPAR $\gamma$ and the BIRC5 promoter in bEnd.3 cells. Data are presented as the mean \pm standard deviation of the mean; $\mathrm{n}=3$ independent experiments. ${ }^{*} \mathrm{P}<0.05$ and ${ }^{* * *} \mathrm{P}<0.01$ v8. promoter-WT with pcDNA4.1. (D) Chromatin immunoprecipitation assay of bEnd.3 cells using mouse monoclonal PPAR $\gamma$ and negative control IgG. Data are presented as the mean \pm standard error of the mean; $n=3$ independent experiments; ${ }^{* *} \mathrm{P}<0.01$ vs. IgG group. (E) Electrophoretic mobility shift assay and supershift assay of PPAR $\gamma$ binding with mouse BIRC5 promoter probes. BIRC5, baculoviral IAP repeat-containing 5; MUT, mutated; OGD, oxygen-glucose deprivation; PPAR $\gamma$, proliferator-activated receptor $\gamma$; WT, wild-type.

provide a novel therapeutic strategy for the treatment of diseases such as stroke.

Cell culture models of cerebrovascular endothelium are essential for exploring the molecular mechanisms of ischemic injury $(18,25-27)$. The present study established an OGD-induced apoptotic injury model using the mouse microvascular endothelial cell line bEnd. 3 and found the most suitable duration time $(12 \mathrm{~h})$ of this model, which may facilitate the future study of ischemic injury. Similar to previous studies $(3,12,28)$, the present study revealed that PPAR $\gamma$ protein expression was reduced in this established model. In order to further investigate the biological functions of PPAR $\gamma$, a PPAR $\gamma$ overexpressed cell model was established by transfecting bEnd 3 cells with PPAR $\gamma$ overexpression plasmid. Cell proliferation and apoptosis assay demonstrated that PPAR $\gamma$ may act as a vascular protective agent in the OGD treated cell model. PAR $\gamma$ activation has been reported to stimulate proliferation and attenuate apoptosis in endothelial progenitor cells through PPAR $\gamma$-dependent signaling cascades $(8,29,30)$. Results from another study also indicated that PPAR $\gamma$ may inhibit $\mathrm{H}_{2} \mathrm{O}_{2}$-induced apoptosis of bEnd.3 cells by upregulating the expression level of 14-3-3 $(5,10)$. It is hypothesized that PPAR $\gamma$ and its ligands may serve as protective agents in the brain during stroke (31).
BIRC5 is a known survival factor in studies on embryogenesis and oncology $(11,32)$, and was recently revealed to serve an important role in cerebral microvascular endothelial cell injury $(33,34)$. However, the regulatory function of PPAR $\gamma$ on BIRC5 was not widely recognized. The present study demonstrated that PPAR $\gamma$ upregulation regulated the expression of BIRC5 both transcriptionally and post-translationally in OGD-treated cells. In addition, the upregulation of BIRC5 may be involved in the acquired resistance from various of noxious stimulations, such as ischemia and other lesions (35). The present study was the first, to the best of the authors' knowledge, to reveal that BIRC5 can be regulated by PPAR $\gamma$ via directly binding in ischemia. In conclusion, the present results demonstrated a cerebrovascular protective role of PPAR $\gamma$ in an ischemia model and identified BIRC5 as a novel target in the pathogenesis of ischemic vascular injury. Therefore, pharmacological activation of either PPAR $\gamma$ or BIRC5 expression may provide potentially therapeutic options for vascular damage induced by ischemia in clinical treatment. The mechanisms of PPAR $\gamma$-mediated protection in endothelial cell damage explained in this study may aid in further understanding the pathogenesis and therapy of cerebral ischemia.

Previous studies have demonstrated that IRC5 may be a pejorative prognostic marker in stage II/III breast 
cancer (36), that silencing of BIRC5 induces neuroblastoma apoptosis (37). BIRC5 is involved in the biological processes of colorectal cancer (38) and can serve as a serum diagnostic and prognostic biomarker of colorectal cancer (39). Silencing BIRC5 promotes hepatoma cell apoptosis (40). However, the expression level of BIRC5 in endothelial cells treated with OGD following PPAR $\gamma$ treatment and the relationship between BIRC5 and PPAR $\gamma$ remain to be elucidated. The present study identified that OGD treatment markedly decreased BIRC5 expression in bEnd.3 cells, and that overexpression of PPAR $\gamma$ recovered this reduction mediated by OGD. In addition, it was identified that PPAR $\gamma$ increased the transcriptional activity of BIRC5, which suggested that BIRC5 is a target of PPAR $\gamma$ regulation. ChIP assay also indicated that there was a significant increase in PPAR $\gamma$ binding to the BIRC5 promoter site, suggesting that PPAR $\gamma$ can interact with BIRC5 promoter. EMSA supershift assay further showed that PPAR $\gamma$ can bind to the BIRC5 promoter. Therefore, it was demonstrated that BIRC5 may be a novel target of PPAR $\gamma$ transcriptional regulation.

\section{References}

1. Pan Q, He C, Liu H, Liao X, Dai B, Chen Y, Yang Y, Zhao B, Bihl J and Ma X: Microvascular endothelial cells-derived microvesicles imply in ischemic stroke by modulating astrocyte and blood brain barrier function and cerebral blood flow. Mol Brain 9: 63, 2016.

2. Xu F, Li J, Ni W, Shen YW and Zhang XP: Peroxisome $\mathrm{p}$ ator-activated receptor- $\gamma$ agonist 15d-prostaglandin J2 medr neuronal autophagy after cerebral ischemia-reperfusion PLoS One 8: e55080, 2013.

3. Wu JS, Tsai HD, Cheung WM, Hsu CY and $L$ ameliorates neuronal apoptosis and ische via suppressing NF- $\mathrm{B}$-Driven p22pho Neurobiol 53: 3626-3645, 2016.

4. Zhang Y, Zhang X, Park TS and thelial cell apoptosis after ischemi activation and

5. Fong WH, Tsai HD, Chen YC, actions of PPAR-gamma against ischemic stroke. Mol Neurobiol 41: 180-186

6. Ketsawatsomkron $P$ an . Dolecular mechanism by peroxisme proliferator activated receptor gamma. Curr Opin Nephrol Hyperten 24: 123-130, 2015.

7. Chu SF, Zhang Z, Zhang W, Zhang MJ, Gao Y, Zuo W, Huang HY and Chen NH: Upregulating the expression of survivin-HBXIP complex contributes to the protective role of IMM-H004 in transient global cerebral ischemia/reperfusion. Mol Neurobiol 54: 524-540, 2017.

8. Zhou Y, Jia S, Wang C, Chen Z, Chi Y, Li J, Xu G, Guan Y and Yang J: FAM3A is a target gene of peroxisome proliferator-activated receptor gamma. Biochim Biophysica Acta 1830: 4160-4170, 2013.

9. Romera C, Hurtado O, Mallolas J, Pereira MP, Morales JR, Romera A, Serena J, Vivancos J, Nombela F, Lorenzo P, et al: Ischemic preconditioning reveals that GLT1/EAAT2 glutamate transporter is a novel PPARgamma target gene involved in neuroprotection. J Cereb Blood Flow Metab 27: 1327-1338, 2007.

10. Wu JS, Cheung WM, Tsai YS, Chen YT, Fong WH, Tsai HD, Chen YC, Liou JY, Shyue SK, Chen JJ, et al: Ligand-activated peroxisome proliferator-activated receptor-gamma protects against ischemic cerebral infarction and neuronal apoptosis by 14-3-3 epsilon upregulation. Circulation 119: 1124-1134, 2009.

11. Fukuda S and Pelus LM: Survivin, a cancer target with an emerging role in normal adult tissues. Mol Cancer Ther 5: 1087-1098, 2006.

12. Zhang Y, Park TS and Gidday JM: Hypoxic preconditioning protects human brain endothelium from ischemic apoptosis by Akt-dependent survivin activation. Am J Physiol Heart Circ Physiol 292: H2573-H2581, 2007.
13. Lu M, Kwan T, Yu C, Chen F, Freedman B, Schafer JM, Lee EJ, Jameson JL, Jordan VC and Cryns VL: Peroxisome proliferator-activated receptor gamma agonists promote TRAIL-induced apoptosis by reducing survivin levels via cyclin $\mathrm{D}_{3}$ repression and cell cycle arrest. J Biol Chem 280: 6742-6751, 2005.

14. Wang Y, Tan H, Xu D, Ma A, Zhang L, Sun J, Yang Z, Liu Y and Shi G: The combinatory effects of PPAR- $\gamma$ agonist and survivin inhibition on the cancer stem-like phenotype and cell proliferation in bladder cancer cells. Int J Mol Med 34: 262-268, 2014

15. Yamashita-Sugahara Y, Tokuzawa Y, Nakachi Y, Kanesaki-Yatsuka Y, Matsumoto M, Mizuno Y and Okazaki Y: Fam57b (family with sequence similarity 57, member B), a novel peroxisome proliferator-activated receptor $\gamma$ target gene that regulates adipogenesis through ceramide synthesis. J Biol Chem 288: 4522-4537, 2013.

16. Cao G, Jiang N, Hu Y, Zhang Y, Wang G, Yin M, Ma X, Zhou K, Qi J, Yu B and Kou J: Ruscogenin attenuates cerebral ischemia-induced blood-brain barrier dysfunction by suppressing TXNIP/NLRP3 inflammasome activation and the MAPK pathway. Int J Mol Sci 17: E1418, 2016

17. Gentil BJ, Minotti S, Beange M, Baloh RH, Julien JP and Durham HD: Normal role of the low-molecular-weight neurofilament protein in mjtochondrial dynamics and disruption in charcot-marie-tooth disease. FASEB J 26: 1194-1203, 2012.

18. Ma X, Zhang H, Pan Q, Zhao Y, Chen J, Zhao B and Chen Y: Hypoxia/aglycemia-induced endothelial barrier dysfunction and tight junction protein downregulation can be ameliorated by citicoline. PLoS One 8: e82604, 2013.

19. Li YN, Pan R, Qin XJ, Yang WL, Qi Z, Liu W and Liu KJ: Ischemic neurons activate astrocytes to disrupt endothelial barrier via increasing VEGF expression. J Neurochem 129: 120-129, 2014.

ivak KJ and TD Schnittgen: Analysis of relative gene expreson data using real-time quantitative PCR and the 2(-Delta Delta C(T) method. Methods 25: 402-408, 2001.

21. Hussain AR, Ahmed SO, Ahmed M, Khan OS, Al Abdulmohsen S, Platanias LC, Al-Kuraya KS and Uddin S: Cross-talk between $\mathrm{NF}-\kappa \mathrm{B}$ and the PI3-kinase/AKT pathway can be targeted in primary effusion lymphoma (PEL) cell lines for efficient apoptosis. PLoS One 7: e39945, 2012.

. Yin KJ, Deng Z, Hamblin M, Xiang Y, Huang H, Zhang J, Jiang X, Wang Y and Chen YE: Peroxisome proliferator-activated receptor delta regulation of miR-15a in ischemia-induced cerebral vascular endothelial injury. J Neurosci 30: 6398-6408, 2010.

23. Arsenijevic D, de Bilbao F, Plamondon J, Paradis E, Vallet P, Richard D, Langhans W and Giannakopoulos P: Increased infarct size and lack of hyperphagic response after focal cerebral ischemia in peroxisome proliferator-activated receptor beta-deficient mice. J Cereb Blood Flow Metab 26: 433-445, 2006.

24. Zhang Y, Wang T, Yang K, Xu J, Ren L, Li W and Liu W: Cerebral microvascular endothelial cell apoptosis after ischemia: Role of enolase-phosphatase 1 activation and aci-reductone dioxygenase 1 translocation. Front Mol Neurosci 9: 79, 2016.

25. Sun H, Xiong W, Arrick DM and Mayhan WG: Low-dose alcohol consumption protects against transient focal cerebral ischemia in mice: Possible role of PPAR $\gamma$. PLoS One 7: e41716, 2012.

26. Deng Y, Xiong D, Yin C, Liu B, Shi J and Gong Q: Icariside II protects against cerebral ischemia-reperfusion injury in rats via nuclear factor- $\kappa \mathrm{B}$ inhibition and peroxisome proliferator-activated receptor up-regulation. Neurochem Int 96: 56-61, 2016.

27. Green DE, Sutliff RL and Hart CM: Is peroxisome proliferator-activated receptor gamma (PPAR $\gamma$ ) a therapeutic target for the treatment of pulmonary hypertension? Pulm Circ 1: 33-47, 2011.

28. Mysiorek C, Culot M, Dehouck L, Derudas B, Staels B, Bordet R, Cecchelli R, Fenart L and Berezowski V: Peroxisome-proliferator-activated receptor-alpha activation protects brain capillary endothelial cells from oxygen-glucose deprivation-induced hyperpermeability in the blood-brain barrier. Curr Neurovasc Res 6: 181-193, 2009.

29. Chen YC, Wu JS, Tsai HD, Huang CY, Chen JJ, Sun GY and Lin TN: Peroxisome proliferator-activated receptor gamma (PPAR- $\gamma$ ) and neurodegenerative disorders. Mol Neurobiol 46: 114-124, 2012.

30. Zeng Y, Xie K, Dong H, Zhang H, Wang F, Li Y and Xiong L: Hyperbaric oxygen preconditioning protects cortical neurons against oxygen-glucose deprivation injury: Role of peroxisome proliferator-activated receptor-gamma. Brain Res 1452: 140-150, 2012. 
31. Gupta D, Jetton TL, Mortensen RM, Duan SZ, Peshavaria M and Leahy JL: In vivo and in vitro studies of a functional peroxisome proliferator-activated receptor gamma response element in the mouse pdx-1 promoter. J Biol Chem 283: 32462-32470, 2008.

32. He F, Qu F and Song F: Aspirin upregulates the expression of neuregulin 1 and survivin afterfocalcerebralischemia/reperfusion in rats. Exp Ther Med 3: 613-616, 2012.

33. Liu ZJ, Liu HQ, Xiao C, Fan HZ, Huang Q, Liu YH and Wang Y: Curcumin protects neurons against oxygen-glucose deprivation/reoxygenation-induced injury through activation of peroxisome proliferator-activated receptor- $\gamma$ function. J Neurosci Res 92: 1549-1559, 2014.

34. Liu N, Zhang Y, Fan L, Yuan M, Du H, Cheng R, Liu D and Lin F: Effects of transplantation with bone marrow-derived mesenchymal stem cells modified by Survivin on experimental stroke in rats. J Transl Med 9: 105, 2011.

35. Fiatte C, Huin C, Collet P, Plenat F, Dauca M and Schohn H: Expression of PPARgamma is reduced by medium supplementation with L-glutamine in human colorectal Caco-2 cells. Int J Mol Med 22: 825-832, 2008.

36. Hamy AS, Bieche I, Lehmann-Che J, Scott V, Bertheau P, Guinebretiere JM, Matthieu MC, Sigal-Zafrani B, Tembo O, Marty M, et al: BIRC5 (survivin): A pejorative prognostic marker in stage II/III breast cancer with no response to neoadjuvant chemotherapy. Breast Cancer Res Treat 159: 499-511, 2016.
37. Lamers F, van der Ploeg I, Schild L, Ebus ME, Koster J, Hansen BR, Koch T, Versteeg R, Caron HN and Molenaar JJ: Knockdown of survivin (BIRC5) causes apoptosis in neuroblastoma via mitotic catastrophe. Endocr Relat Cancer 18: 657-668, 2011.

38. Li PL, Zhang X, Wang LL, Du LT, Yang YM, Li J and Wang CX MicroRNA-218 is a prognostic indicator in colorectal cancer and enhances 5-fluorouracil-induced apoptosis by targeting BIRC5. Carcinogenesis 36: 1484-1493, 2015.

39. Wang H, Zhang X, Wang L, Zheng G, Du L, Yang Y, Dong Z, Liu Y, Qu A and Wang C: Investigation of cell free BIRC5 mRNA as a serum diagnostic and prognostic biomarker for colorectal cancer. J Surg Oncol 109: 574-579, 2014.

40. Wang Q, Shu R, He H, Wang L, Ma Y, Zhu H, Wang Z, Wang S, Shen G and Lei P: Co-silencing of Birc5 (survivin) and Hspa5 (Grp78) induces apoptosis in hepatoma cells more efficiently than single gene interference. Int J Oncol 41: 652-660, 2012.

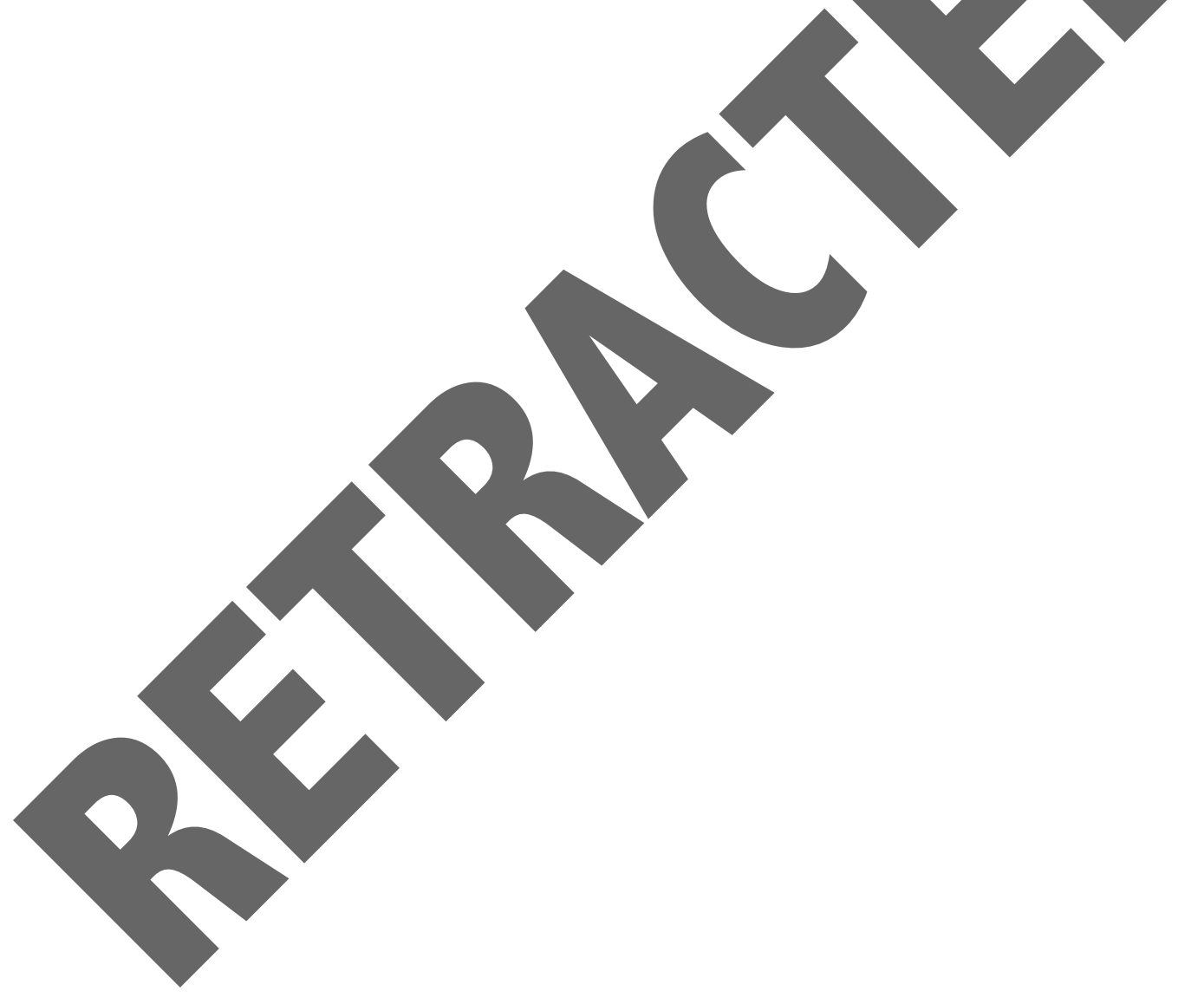

